\title{
HERMENÉUTICA Y EDIFICACIÓN PRIVADA
}

\section{Diana María López}

"En Verdad y Método, Gadamer deja claro que la hermenéutica no es un "método para conseguir la verdad" (...) Más bien lo que hace (...) a grandes rasgos, es preguntar qué conclusiones se pueden deducir del hecho de que tenemos que practicar la hermenéutica (...) Su libro es una nueva descripción del hombre que intenta colocar la imagen clásica dentro de otra más amplia y, por tanto, de "distanciar" la problemática filosófica consagrada en vez de ofrecer un conjunto de soluciones a la misma". (RORTY, R. La filosofía y el espejo de la naturaleza)

Para Richard Rorty la tradición filosófica occidental, al menos desde el siglo XVII, ha sido seducida por la metáfora de que la mente es el "espejo" del mundo. A su vez, esta metáfora ha inspirado el enfoque de filósofos que, en virtud de sus investigaciones acerca del método, coinciden en reivindicar la "privilegiada" posición de la filosofía tanto para evaluar la exactitud de nuestras representaciones mentales, como para asignarle a las diversas clases de representaciones (científicas, morales, estéticas, ...) su respectiva importancia cultural y social. Más aún, y a pesar de las importantes variaciones y de los intentos relativamente exitosos de escapar de aquella imagen, la continuidad de esta concepción puede verificarse tanto en el universalismo contemporáneo de raíz Kantiana como en la "epistemología naturalizada" desde Hume a 
Quine. De una u otra forma, estos proyectos intentan identificar las reglas invariables que regulan todo discurso reconocido como "científico" (normal) con el paradigma normativo -trascendental y ahistórico- capaz de garantizar las condiciones formales universales de todo consenso racional posible. ${ }^{1}$

En La filosofía y el espejo de la naturaleza -obra en la que nos detendremos en sus últimos capítulos-, Rorty contempla tanto el fracasado intento crítico de posiciones post-analíticas que no logran disociar "filosofía" de "epistemología", como la consideración de un modelo alternativo que es presentado indistintamente como "pragmatismo", "hermenéutica" y "discurso edificante". Nos proponemos evaluar en este orden, el alcance de las sustanciales variaciones de sentido que logran producirse en las categorías gadamerianas al ser interpretadas en clave neo-pragmatista $\mathrm{y}$, por ende, recontextualizadas desde una lectura que pone de manifiesto aspectos no presentes, al menos de manera inmediata, en la hermenéutica continental.

\footnotetext{
${ }^{1} \mathrm{Si}$ bien muchas de las consideraciones que Rorty defiende merecen ser analizadas independientemente de su peculiar apreciación del desarrollo histórico de la filosofía, es inevitable encontrar a cada una de sus afirmaciones inseparablemente articuladas con sus "metatesis" acerca del pasado de nuestra disciplina. Una de ellas, sujeta a un polémico debate desde que la formulara por primera vez en la década del " 70 , es la de la metáfora del "espejo": la insistencia en relacionar el modelo de la "mente ocular", "espejismo", "fundacionalismo" y "verdad" dió lugar a no pocas reacciones en razón de lo que se ha juzgado como el carácter "inauténtico"” de sus interpretaciones. La respuesta de Rorty al respecto se ha movido en un mismo sentido: la precisión histórica es un objetivo menor cuando lo que está en juego es establecer un "diálogo" con el pasado que permita reorientar la tarea del filósofo en el amplio marco de la cultura. El horizonte de la "narratividad" que Rorty propone ahora para toda reconstruccịón histórica, operará como trasfondo desde el cual poder interrogarnos menos por la objetividad de sus juicios acerca de tesis canónicas de la filosofía de Occidente, que por la "plausibilidad" y "fecundidad" de sus controvertidas lecturas.
} 


\section{Una cuestión central: el tema de la comprensión}

La hermenéutica para H.G. Gadamer, lejos de circunscribirse a una metodología de lectura de textos que pretenda en aras de la objetividad desconocer el carácter mediado y mediador de todo contenido transmitido en el tiempo, se configura como una reflexión general acerca de la comunicación humana orientada a la interpretación de toda transmisión histórica de sentido. Esto conduce no sólo a revisar la paradigmática pretensión que las ciencias positivas reclaman para sí en lo que al conocimiento se refiere, sino más aún, a postular concepciones de "saber" y de "verdad" lo suficientemente amplias como para recoger todas aquellas reflexiones que tienen en el problema de la comprensión, su punto de partida.

Este punto de partida, supone abandonar la canónica oposición "objetivo-subjetivo", en virtud de que lo que se comprende nunca es asimilable a la autotransparencia categorial de un yo monológicamente autofundado y ahistóricamente erigido en conciencia absoluta. Por el contrario, todo "texto", más allá de ser un "factum" que exige fidelidad a la intencionalidad que le dió origen, se redefine como estimulante incitación a ser traducido en múltiples y revisables lecturas que nunca terminan de agotar un contenido siempre recreable desde contextos nuevos. En consecuencia, al abrirse al sentido del pasado, toda interpretación "funde horizontes" como "conversación", trascendiendo los clausos y estáticos límites dentro de los cuales suelen colocarse al autor y al intérprete.

Desde ya, ésto postula una diversa concepción de la verdad y un reacomodamiento del lugar del método en el marco de la filosofía, al definirse en clara oposición a perspectivas inspiradas en las pretensiones de certeza de la "episteme" moderna. Refi- 
riéndose a la escuela histórica, Gadamer nos dice:

\begin{abstract}
"La ciencia histórica del Siglo XIX (...) se entiende a símisma precisamente como realización de la Ilustración (...) como el paso al conocimiento objetivo del mundo histórico, capaz de igualar en dignidad al conocimiento de la naturaleza de la ciencia moderna". ${ }^{2}$
\end{abstract}

Por su parte, líneas contemporáneas que podrían ubicarse desde la aparición del famoso artículo de Hempel sobre "La función de las leyes generales en la historia" 3 , claramente influenciadas por el ideal de un saber que elevara a la altura del entendimiento el sentido total del devenir, confluyen en la indiferencia frente a los límites de todo horizonte histórico, y, por ende, en el supuesto de que lo singular y contingente es superfluo cuando es visto desde el punto arquimédico de una razón que opera conforme a los cánones de las ciencias hipotético-deductivas: la arbitrariedad de la mutilación de la historia sólo se justifica en nombre de la "arquitectónica de la Historia". La comprensión, entendida en este contexto como el acto por el cual una subjetividad separada de su entorno es capaz de "explicar" el sentido total del devenir, se constituye sobre dos presupuestos igualmente vitales para sostener el "edificio del saber": la negación de la propia situación -desde la cual siempre se conoce-, y la fe ciega en los procedimientos de una cientificismo histórico caracterizado por desconocer la inserción finita de todo pensar. Desde la hermenéutica, la consecuencia de esta perspectiva es tanto una

${ }^{2}$ Gadamer, H.G., Verdad y Método, Salamanca, Sígueme, 1977, p. 342. (Desde ahora VM)

${ }^{3}$ Hempel, C.G.., "La función de las leyes generales de la historia" en La explicación científica, Buenos Aires, Paidós, 1979. 
deformación del conocimiento en cuanto que el objeto de estudio, el pasado, se convierte en naturaleza a la mano, inerte y troquelada -mero objeto de repetición-, como la desustanciación atemporal de "lo histórico", cuya fecundidad no puede ya recuperarse en un momento posterior de síntesis especulativa ${ }^{4}$.

La postura teórica de Gadamer sólo se gana en la medida en que logra alcanzar una distancia radical de esta línea de pensamiento reconociendo, por un lado, el carácter provisional de todo conocimiento, y por otro, el supuesto de que el punto de partida de toda interpretación no puede encontrarse sino en la afirmación de la opacidad y extrañeza del pasado, el cual en su alteridad de tiempo sido, sólo podrá ser descubierto en el propio fluir de su aconte$c e r$, presencia actual y operante en un presente inagotable con vistas a lo por-venir.

"El tiempo -nos dice- ya no es primariamente un abismo que hubiera de ser salvado porque por sí sería causa de división y lejanía, sino que es en realidad el fundamento que sustenta el acontecer en el que tiene sus raíces el presente. La distancia en el tiempo no es en consecuencia algo que tenga que ser superado, por el contrario de lo que se trata es de reconocer la distancia en el tiempo como una posibilidad positiva y productiva del comprender. No es un abismo devorador, sino que está cubierto por la continuidad de la procedencia a cuya luz se nos muestra todo lo transmitido". (VM - 368)

\footnotetext{
${ }^{4}$ Para la ampliación de este tema pueden verse: Danto, A.C., Historia y narración. Ensayo de filosofía analítica de la historia., Barcelona, Paidós, 1989. Duque, F. Los caminos de la tradición, Barcelona, Anthropos, 1989. Yturbe, C., "El conocimiento histórico" y Duque, F., "Historia e historicidad en el existencialismo y la hermenéutica" en Mates, R. (Ed.): Filosofía de la historia, Madrid, Trotta, 1993.
} 
El saber histórico comprendido como "mediación entre presente y pasado", se torna viable ahora sobre la base de una "fusión de horizontes" supuestamente independientes.

"El horizonte del presente -expresa Gadamer- no se forma en absoluto sin el pasado. Un horizonte del presente para si no existe como tampoco horizontes que hubiese que ganar". En este sentido “...no debe concebirse a la comprensión misma tanto como un acto de la subjetividad sino más bien como un ingreso en el acontecimiento de la tradición". (VM 289)

Frente a la concepción de la filosofía que reconoce en toda pretensión de conocimiento verdadero una irrecusable remisión a un dominio de entidades que se hallan más allá de nuestras representaciones, la filosofía en el marco de la "conversación que somos" -expresión que Gadamer toma de Hölderling- se redefine desde categorías nuevas, desacralizando por un lado, la lógica iluminista fuerte de toda concepción que vea en su desarrollo el despliegue de la "razón", y por otro, entablando con la historia una relación más cauta inspirada por la intención de "dejar hablar a los textos", de captar la interacción de sus dimensiones complejas sin reducirlas a esquemas unívocos de racionalidad.

En esta línea, el neo-contextualismo de Richard Rorty, orientado a demostrar la obsolescencia de posiciones fundacionalistas, descubre en el pensamiento gadameriano la toma de conciencia del "ideal de fundamentación", y por ende, la posibilidad de distanciarse de la epistemología en concordancia con los resultados de la reflexión de Nietzsche y Heidegger, cuya herencia vive propiamente en la hermenéutica.

"Hay que dejar de lado esa imagen clásica de los 
seres humanos (aquella de que el hombre tiene una esencia, a saber descubrir esencias) antes de poder dejar de lado una filosofía cuyo centro esté en la epistemología. El intento de conseguirlo tiene el nombre de "hermenéutica". 5

\section{El etnocentrismo de R. Rorty: un intento problemático de apro- piación de la hermenéutica gadameriana}

Es justamente la hermenéutica gadameriana la que ofrece a Rorty el "desmarque" de la epistemología, en el sentido de la realización de sus esperanzas de "inconmensurabilidad" y de ausencia de criterios ajenos a las propias creencias y prácticas sociales. Sin embargo, es precisamente en su singular "interpretaciónapropiación" de categorías centrales del pensamiento de Gadamer, donde descubrimos diferencias relevantes sobre las que consideramos importante detenernos.

En el capítulo sobre "El lenguaje como medio de la experiencia hermenéutica", al referirse Gadamer a la conversación, nos dice:

"Acostumbramos a decir que llevamos una conversación, pero la verdad es que, cuanto más auténtica es la conversación, menos posibilidades tienen los interlocutores de "llevarla" en la dirección que desearian. De hecho la verdadera conversación no es nunca la que uno habría querido llevar. Al contrario, en general sería más correcto decir que "entramos" en una conversación, cuando no que nos "en

${ }^{5}$ Rorty, R., La filosofía y el espejo de la naturaleza, Madrid, Cátedra, p. 323 (desde ahora FEN). 
redamos" en ella. Una palabra conduce a la siguiente, la conversación gira hacia aquí o hacia allá, encuentra su curso y su desenlace, y todo esto puede quizá llevar alguna clase de dirección pero en ella los dialogantes son menos los directores que los dirigidos. Lo que "saldrá" de una conversación no lo puede saber nadie por anticipado". (VM - 461)

El espíritu de las palabras de Gadamer, se halla claramente presente en la utilización que Rorty hace de la noción de conversación. Conversación es para Rorty la forma de la filosofía cuando ésta se comprende exclusivamente desde el abandono de los ideales de fundamentación y en el marco de la ausencia de criterios que remitan a los hablantes a instancias universales para juzgar las pretensiones de validez de argumentaciones y de normas. Negar la existencia de esa base neutral, significa que las razones a favor o en contra de un punto de vista particular no pueden ser determinadas por adelantado, apelando o remitiendo a nociones preexistentes de "verdad", "realidad" o "ley moral". Ellas están más bien determinadas en el curso de la conversación con relación a las "ventajas o desventajas concretas" que tiene un punto de vista dado. Nuestras razones para asumir una perspectiva científica, política o aún estética como opuesta a otra son razones debatidas en diálogo y abiertas a revisión o rechazo dependiendo de las otras opciones que sean propuestas.

"La hermenéutica ve las relaciones entre varios discursos como los cabos dentro de una posible conversación, que no presupone ninguna matriz disciplinaria que una a los hablantes, pero donde nunca se pierde la esperanza de llegar a un acuerdo". (FEN - 289).

Ni subjetividad trascendental, ni condiciones a priori, ni 
filósofos "guardianes de la racionalidad", ... para Rorty, la filosofía en el marco de la conversación de la humanidad, se articula muy bien con la concepción hermenéutica de conocimiento tal cual la descubre en el pensamiento de Gadamer. Para Rorty, la hermenéutica se define por

“...la capacidad para describir una actitud interesada no tanto en lo que hay ahí fuera en el mundo, $o$ en lo que ocurrió en la historia, cuando en lo que podemos sacar de la naturaleza y de la historia para nuestros propios usos". Es decir “...para encontrar una forma nueva y más interesante de expresarnos a nosotros mismos, $y$, por tanto, de arreglárnosla con el mundo". (FEN-325)

Consideramos que este texto es particularmente estimulante para establecer una contrastación con los escritos de Gạdamer, a los fines de echar luz sobre aquellos tópicos en que ambos pensamientos se nos presentan como irreconciliables.

Gadamer abandona el "moderno concepto de método", no el método. Se desalinea del "conocimiento objetivo y completo del mundo histórico" tal cual lo formulara la ciencia de la historia del siglo XIX, no de la objetividad del conocimiento. Se aparta de la verdad como "mera desconexión de los propios intereses sobre el objeto", no de la verdad.

Es en la relación "circular" de la comprensión con la condición hermenéutica de la pertenencia a una tradición, donde Gadamer encuentra la redefinición de estas categorías. Así nos dice :

"...la autoridad es de hecho una fuente de prejui-

cios. Pero esto no excluye que pueda ser también 
una fuente de verdad.".(VM - 346)

Por su parte, para Rorty, aquel conocimiento que se supone procede de la aplicación de métodos confiables y que encuentra su forma más acabada en la "moderna ciencia natural", debe ser desplazado ahora por la noción de "edificación".

En el Capítulo VII de La filosofía y el espejo de la naturaleza, Rorty se ocupa de establecer la diferencia entre discursos "conmensurables" y discursos "inconmensurables" a fin de divorciar el ámbito de la "epistemología" del de la "hermenéutica", terreno este último en el cual, ante la ausencia de "matrices disciplinarias" y "vocabularios maestros" que gocen del suficiente consenso para resolver problemas, es posible proceder

“...no reductivamente y con la esperanza de descu-

- brir un nuevo ángulo de las cosas" (FEN-292)

La adopción de la noción kuhneana de "paradigma" (293) y el abandono de la distinción tradicional entre "espíritu" y "naturaleza", que justificara en el pasado la diferencia epistemológica entre "ciencias humanas" y "ciencias naturales" (311), configuran la línea argumentativa que conducirá sutilmente a las dos conclusiones más importantes de su obra: por un lado, a la aleación ahora casi incondicional- entre "hermenéutica" y "edificación" y, finalmente, al desplazamiento prácticamente irreversible, de la "filosofía sistemática" a la "filosofía edificante".

Lo que Rorty llama discursos "conmensurables" son aquellos que operan con criterios de construcción de consensos confiables. Contrariamente, los discursos son "inconmensurables" o "anormales" cuando se cuestionan las orientaciones básicas. Por lo general, las conversaciones anormales, en virtud de que no operan dentro de un entendimiento dado por sentado acerca de cuáles 
consideraciones deben ser tomadas por "correctas", "válidas" o "verdaderas", tienden tarde o temprano a convertirse en "normales", es decir, a disolverse para alcanzar el consenso. Ocasionalmente, no obstante, los discursos anormales se detienen ante este paso autotrascendente y se contentan con el "disenso interesante y fructífero". Es decir, se convierten en suficientes para ellos mismos. A esta altura los discursos anormales, adoptan la cualidad que Rorty denomina "edificante":

“....utilizaré el término 'edificación' para referirme a este proyecto de encontrar nuevas formas de hablar que sean más interesantes y provechosas". (...) "Se supone que el discurso que edifica es anormal, que nos saca de nosotros mismos por la fuerza de lo extraño para ayudar a convertirnos en seres nuevos" (FEN - 325)

Si la conmensurablidad indica que ha concluído el ciclo, por ejemplo de una "revolución científica", y que los participantes en una controversia han retornado a un marco normal compartido, la hermenéutica se vuelve necesaria cada vez que existe un defecto de comunicación entre los discursos en competencia, ya sea que se produzca entre culturas o entre paradigmas conflictivos de explicación.

"El intento de edificar (...) puede consistir en la actividad hermenéutica de establecer conexiones entre nuestra propia cultura y alguna cultura o periodo exótico, o entre nuestra propia disciplina y otra disciplina que parezca buscar metas inconmensurables con un vocabulario inconmensurable. Pero puede consistir en la actividad 'poética' de elaborar esas metas nuevas, nuevas palabras, nuevas disciplinas..." (FEN - 325) 
Como vemos el esteticismo de Rorty no tiene límites cuando lo que está en juego es "edificar sin ser constructivos". Fiel a sus propósitos, introduce con total libertad la idea de "paradigma" de Kuhn a fin de aplicarla a los discursos en general, inclusive a la filosofía, al punto que ésta se convierte ahora en "conversación interparadigmática".

“...en discurso sobre discursos todavía-inconmensurables..." (FEN - 311)

En consecuencia, dado que no puede existir ninguna verificación objetiva y que el "deseo de verdad" debe ser sustituído por el "deseo de edificación", la confrontación de interpretaciones inconmensurables no se resuelve nunca en función de lo que podría llamarse el encuentro de un nuevo "paradigma" o de la configuración de una nueva "matriz disciplinar" -según la expresión de Kuhn- que autorizara a definir nuevos problemas y los procedimientos correspondientes para resolverlos. La filosofía "edificante", como discurso anormal, no es un paradigma anormal; no es un paradigma y no aspira a ser uno; toda la idea de la filosofía edificante surge de la desconfianza en la filosofía como un área de investigación con sus propios problemas y métodos. No existen "problemas filosóficos" y no se necesitan "teorías filosóficas" para resolverlos. La filosofía permanece así, para Rorty, como una actividad ampliamente cultural e intelectual, cuyo único propósito es

“...sugerir un nuevo juego de lenguaje, con la esperanza de una nueva forma de vida intelectual" 6

De esta manera, el contraste entre "edificación" y "conocimiento", conduce así a la opción por la primera, a la vez que al

${ }^{6}$ Rorty, R., "La filosofía hoy en América" en Consecuencias del pragmatismo, Madrid, Tecnos, 1996, p. 306 
abandono de la confianza depositada en el segundo. El conocimiento de este siglo es la "superstición" del siglo que viene. Por ello, su noción, ya sea que requiera justificación o que sea capaz de darla, debe ser desechada.

“...Una forma de ver la filosofía edificante como amor a la sabiduría -dice Rorty- es verla como el intento de impedir que la conversación degenere en investigación, (...) Los filósofos edificantes no pueden terminar la filosofía, pero pueden ayudar a impedir que llegue al sendero seguro de la ciencia". (FEN - 336)

La opción que propone Rorty no está de acuerdo con el propio Gadamer. No habría en el pensamiento de este último, un desplazamiento de la "indagación" y de la "investigación" hacia la "edificación" en el sentido "literario" de:

“...dejar un espacio abierto a la sensación de admiración que a veces causan los poetas- admiración de que haya algo nuevo bajo el sol, algo que (al menos de momento) no se puede explicar y difícilmente se puede describir". (FEN-334)

sino por el contrario, un horizonte nuevo desde el cual la investigación, la indagación, el conocimiento , ... se redefinen sin renunciar a ellos.

"En el comienzo de toda hermenéutica histórica, dice Gadamer- debe hallarse por lo tanto la resolución de la oposición abstracta entre tradición e investigación histórica, entre historia y conocimiento de la misma. Por tanto, el efecto de la tradición que pervive y el efecto de la investigación histórica forman una unidad efectual cuyo análisis sólo podría 
hallar un entramado de efectos recíprocos". (VM 351)

El conocimiento se entiende por cierto en Gadamer en el marco de la "circularidad de la comprensión". Este "entramado de efectos recíprocos", este hecho de que "nuestro ser finito esté determinado por la autoridad de lo transmitido", es lo que le permite a Rorty levantar los muros de un etnocentrismo -ausente en Gadamer- según el cual, "justificar nuestros compromisos" sólo debe ser entendido en el contexto de la "conversación que somos" y en la forma en que "nosotros" la entendemos. Para Rorty, hemos crecido en un cierto tipo de cultura; hemos formado ciertas expectativas; estamos comprometidos con ciertos valores, y no podemos abandonar ninguno de ellos porque nos identificamos a nosotros mismos en relación a ellos. Este punto de partida, el del reconocimiento insoslayable de "nuestra situación", estaría presente en Gadamer cuando enfatiza que la reflexión crítica no puede socavar nuestra lealtad hacia la autoridad de nuestra tradición, precisamente porque no podemos conocer lo suficiente para rechazarla:

"Lo consagrado por la tradición y por el pasado nos dice- posee una autoridad que se ha hecho anónima, y nuestro ser histórico y finito está determinado por el hecho de que la autoridad de lo transmitido, y no sólo lo que se acepta razonadamente, tiene poder sobre nuestra acción y nuestro comportamiento". (VM - 348)

En ambos autores, la "tradición" se impone sobre la "reflexión", en virtud de que no podemos ir "fuera" para evaluar su racionalidad de acuerdo con un concepto de razón independiente de ella: 
“...la idea de una razón absoluta no es una posibilidad de la humanidad histórica. (...) la razón -dice Gadamer- sólo existe como real e histórica, esto es la razón no es dueña de símisma sino que está siempre referida a lo dado en lo cual se ejerce". (VM 343)

Sin embargo, la posición de Gadamer parece ofrecer opciones que la de Rorty no. El concepto de Gadamer de la importancia de alcanzar un entendimiento con la tradición, incorpora aspectos no existentes en el punto de vista rortyano: las nociones de "distancia en el tiempo", "historia efectual" y "fusión de horizontes", le permiten desarrollar una relación con el propio pasado que no conlleva la simple aceptación por temor a criticarlo injustamente. Más bien, lo que aparece es la incorporación de la crítica como un elemento del entendimiento que integra los diferentes elementos del todo en orden a un punto de vista mejor, en el sentido de más articulado.

"La movilidad histórica de la existencia humana nos dice- estriba precisamente en que no hay una vinculación absoluta a una determinada posición, y en este sentido de que taimpoco hay horizontes realmente cerrados. (...) Este desplazarse no es ni empatía de una individualidad en la otra, ni sumisión del otro bajo los propios patrones; por el contrario, significa siempre un ascenso hacia una generalidad superior, que rebasa tanto la particularidad propia como la del otro. El concepto de horizonte se hace aquí interesante porque expresa esa panorámica más amplia que debe alcanzar el que comprende. Ganar un horizonte quiere decir siempre aprender a ver más allá de los cercano y de lo muy cercano, no desatenderlo, sino precisamente verlo mejor integrándolo en un todo más grande y 
en patrones más correctos”. (VM 374-375)

Gadamer expresa así el reconocimiento de la diversidad desde una perspectiva que al desbordar los intereses de la comunidad a la que se pertenece, abandona la parcialidad de la unilateralidad del propio conocimiento, adoptando un interés por las diferentes culturas y el pasado que no se registraría en Rorty. Para quien

“...Concebir el propio lenguaje, la propia conciencia, la propia moralidad y las esperanzas más elevadas que uno tiene, como productos contingentes, como literalización de lo que una vez fueron metáforas accidentalmente producidas, (ciegas marcas que nuestras acciones llevan ) es adoptar una identidad que le convierte a uno en persona apta para ser ciudadano de un Estado idealmente liberal" 7

Frente a esto cabría argumentar que no es la contingencia lo que confiere identidad. Al estudiar otras culturas, llevar a cabo experimentos científicos, escribir poesía y al examinar nuestra propia historia, lo que uno-aprende no es una serie de hechos no relacionados e irrevocablemente azarosos. Al margen de la preocupación epistemológica por la certeza de los enunciados, la confianza en el propio método o la validez de los hallazgos, lo que uno alcanza es una capacidad para el aprendizaje futuro, para nuevas formas de pensamiento, de expresión y de acción.

Esto último estaría presente en Rorty en su concepto de "edificación", pero la diferencia con Gadamer radica en que la "edificación" reemplaza al "conocimiento" como el objetivo y el

${ }^{7}$ Rorty, R., Contingencia, Ironía y Solidaridad, Barcelona, Paidós, 1991, p. 76, (desde ahora CIS) 
fin del pensamiento, mientras que en la visión de Gadamer hay mucho más que una educación dentro del pluralismo de las "formas-de-enfrentar o maneras-de-superar las cosas". La concepción de Gadamer refleja un proceso de preservación histórica en el cual uno toma conciencia no solamente de los hechos y de sus efectos, sino, lo más importante, aprende cómo ellos deben ser integrados apropiadamente dentro de la vida de cada uno y en la comprensión de uno mismo. Esta visión no sólo no agota el "conocimiento" en una concepción reductiva, sino que, por el contrario, lo amplía y lo enriquece al extenderlo y ponerlo en contacto con el ámbito práctico en el cual se potencia como "experiencia", no en el sentido pragmático de la capacidad de redescribirnos sacando de la historia lo que necesitamos para "arreglárnosla con el mundo" , sino en el de la socrática docta ignorantia de que no tenemos todas las respuestas, y de que siempre estamos a tiempo de aprender "desde" y "con" los otros.

\section{Conclusión}

La hermenéutica, tanto en Gadamer como en Rorty, se ubica resueltamente fuera de los parámetros establecidos por la filosofía de la conciencia y su paradigma epistemológico. La idea de cognición mediada por el lenguaje y ligada a la acción, así como el virtual desplazamiento de la reconstrucción racional a la praxis creadora, se articulan en orden al rechazo de los medios de comprensión que llevaron a postular el carácter necesario del espíritu humano y la capacidad "legitimatoria" de nuestra disciplina.

Desde Dilthey, la hermenéutica ha signado el desarrollo de la filosofía posterior, en el sentido de que no podemos comprender una expresión simbólica a menos que tengamos un preentendimiento de su contexto, ya que no poseemos una libertad 
ilimitada para convertir el conocimiento del trasfondo no-problemático de nuestra cultura, en conocimiento explícito. Dado que esta red es, al mismo tiempo holista y particularista, nunca puede ser auto-transparentemente comprendida mediante un análisis general y abstracto. Sin embargo, en Rorty -a diferencia de lo que considera Gadamer-, el contextualismo se radicaliza al dar por concluído el énfasis en el carácter representacional del lenguaje para sustituirlo por su función narrativa.

Rorty propone una "proliferación" de nuevos vocabularios, ninguno de los cuales debe ser privilegiado para que continúe "encendida" la conversación de Occidente. El valor de un lenguaje -el ser elegido y no desechado-, depende exclusivamente de cuán útil es para organizar nuestra vida y para desarrollar un intercambio de opiniones intelectualmente productivo. No obstante, toda la retórica rortyana a través de la cual expone insistentemente el carácter "libre" y "abierto" de todo diálogo no puede evitar presuponer que todo lenguaje es "significativo" de algún modo, ni excluir la presencia de alguna noción de "verdad" operando en el seno mismo del discurso, aunque más no sea para actuar como instrumento de juicio del grado de "productividad" alcanzado. Aún aceptando que debamos evitar el escepticismo y el idealismo, nos queda todavía analizar la verdad como relación objetivamente independiente entre representaciones referenciales y el mundo, al menos claro está, que estemos dispuestos a reconocer que la "conversación edificante" no va más allá de un "juego metafórico" que solamente podría ser defendido como "discurso de ficción"».

Con Rorty la noción "fuerte" de verdad se diluye en la ausencia de rigor de un diálogo difuso, en un intercambio colecti-

\footnotetext{
${ }^{8}$ Ver Rorty, R., "Hay algún problema con el discurso de ficción?", en Consecuencias del pragmatismo, op.cit., pp. 182-216.
} 
vo de significados que no se apoyan en ningún referente estable. Este itinerario no reconoce grises. O se es "sistemático" o se es "edificante". La "hermenéutica edificante", no es un llamado a considerar los mismos problemas desde otra perspectiva o la oportunidad para analizar un nuevo conjunto de problemas. No hay "integración" ni "construcción"; no hay "sospecha" ni "desenmascaramiento" "...sólo una especie de terreno experimental y creativo en el que conviven -circunstancial y contingentemente-, diferentes clases de interpretaciones gestadas en diferentes contextos para diferentes propósitos. Sin marcos teóricos definidos, sin vocabularios "maestros" ni avales de argumentos epistemológicos y semánticos, cabe preguntarnos: cuál es la virtud intrínseca en dejar el campo de la actividad interpretativa trabajosamente ganada por la hermenéutica- en indeterminación prístina y sin pretensiones de validez más allá del contexto en que las opiniones en competencia son expuestas?

Nadie niega el carácter "efectista" que esta posición pueda tener para quienes -como Rorty-, se esfuerzan por arrancar los últimos suspiros de vida al fundacionalismo, al cientificismo, al logo-centrismo a-histórico, etc., pero también debe concederse que su consecuencia es una "noche en la que todos los gatos son pardos". No se trata solamente de "describir con exactitud", ni de oponerse al "deseo", o aún a la necesidad de ofrecer siempre interpretaciones nuevas desde puntos de vista variables y en función de orientaciones que anticipen el cumplimiento de expectativas futuras. Lo discutible son las condiciones bajo las cuales esta clase de proliferación debe suceder. Uno de los aportes más importantes de la hermenéutica filosófica, es el reconocimiento de las elaboraciones de la conciencia histórico-efectiva con sus pre-concepciones y

${ }^{9}$ Ferraris, M., "Envejecimiento de la 'escuela de la sospecha'", en El pensamiento débil, Madrid, Cátedra, 1983, pp. 169-191. 
pre-juzgamientos, y, por ende, la aceptación de diferencias de intereses, énfasis y perspectivas. Pero se trata de aquel tipo de diferencias que sin renunciar al interés por la verdad -uno de los aspectos principales por otra parte cuando se debate un "conflicto de interpretaciones"-, podrían reconciliarse en una visión más abarcadora. Según Gadamer es precisamente esta idea de totalidad de una unidad de sentido ideal, la que estructura el discurso hermenéutico:

“...es muy posible que diversos proyectos de elaboración rivalicen unos con otros hasta que pueda establecerse univocamente la unidad del sentido; la interpretación empieza siempre con conceptc's previos que tendrán que ser sustituídos progresivamente por otros más adecuados. Y es todo este constante reproyectar, en el cual consiste el movimiento del sentido del comprender e interpretar..." (VM - 333)

En síntesis, las coincidencias entre Gadamer y Rorty, no alcanzan para disimular las profundas diferencias que los sepa$\operatorname{ran}^{10}$. Para Rorty, la filosofía centrada en la epistemología es un

\footnotetext{
${ }^{10}$ Richard Bernstein, en el Capítulo 2: "Cuál es la diferencia que marca una diferencia?" de su libro: Perfiles filosóficos, México, Siglo XXI, 1991, pp. $72-$ 111: no reconoce diferencias sustanciales en el pensamiento de ambos autores, sino más bien un "terreno común" que, compartido con Habermas, habilitaría para considerarlos bajo el nombre de "humanismo pragmático no fundacional". En una publicación posterior (la primera edición en inglés de Perfiles filosóficos es de 1986): "One step forward, to steps backward. Richard Rorty on liberal democracy and philosophy", Political Theory, 15, n. 4 (november 1987), pp. 538-563: Bernstein se muestra sensiblemente más crítico: "Aquí es útil contrastar a Gadamer con Rorty. Para Gadamer (y Dewey) siempre estamos involucrados de antemano en el 'suceder' del entendimiento, de la interpretación y de la apropiación. Pero para Gadamer cuando nos involucramos en el diálogo, ya sea con otra persona, con un texto o una tradición, siempre existe 'otro' a quien respondemos, que nos habla y nos limita. Existe un genuino
} 
episodio dentro de la historia intelectual de Occidente, la cual no es sino una conversación que puede mantenerse en la medida en que se asuma la fugacidad y rápida obsolescencia de los vocabularios y en tanto que los filósofos no tomen ya en serio su lugar de "funcionarios de la humanidad", capaces de relacionarnos con un dominio que trascienda lo humano. De este modo, la hermenéutica es, al tiempo que la ocasión de abandonar la epistemología que nos descubriera atravesados por un mismo "logos", la oportunidad para poder hablar con vocabularios ilimitadamente recreables, sin garantías epistemológicas ni metafísicas, y en función del logro de "nuestros propios fines".

\begin{abstract}
"No hay nada que sea una 'filosofía primera': ni la metafísica, ni la filosofía del lenguaje ni la filosofía de la ciencia. Pero una vez más y por última vez-
\end{abstract}

movimiento de idea y vuelta que nos permite constituir un 'nosotros' que es más que una proyección de mis propios deseos y creencias idiosincráticas. Pero para Rorty nunca parece existir limitaciones efectivas para un 'mi' $y$ ' 'mis' interpretaciones. Es por eso que las constantes referencias de Rorty a un 'nosotros', a una tradición común, a un consenso compartido parecen huecas -nada más que una etiqueta de un 'mi' proyectado-". (La traducción es nuestra). Puede verse la respuesta de Rorty en: "Thugs and theorists. A reply to Bernstein", pp. 564-580, de la misma publicación. Por su parte, Julio De Zan en su completo artículo "Pensamiento reconstructivo y mundo simbólico", Tópicos, n. 4, 1996, pp. 99-126, reivindica el "paso adelante" dado por Habermas en relación con Gadamer y Rorty al considerar, en el marco de la "pragmática universal”, el carácter reflexivo de la hermenéutica en cuanto que “...el propio Verstehen, la interpretación, se puede comprender y explicar mejor si lo entendemos como la reconstrucción racional del sentido y las pretensiones de validez de las expresiones". Ver en la misma publicación el interesante trabajo de Cleres Kant sobre: "Claves dialécticas de la hermenéutica gadameriana", pp. 127-157, en el cual la autora muestra la progresiva configuración de la hermenéutica de Gadamer como una "dialéctica dialógica marcadamente original" (en contraste histórico con Platón, Hegel y Heidegger) y su significativa diferencia con perspectivas "instrumentalistas" del lenguaje. 
nos dice- esa afirmación acerca de la filosofía misma es sólo una sugerencia terminológica más, hecha en favor de la misma causa: la causa de proporcionar a la cultura liberal contemporánea un léxico que sea enteramente suyo, depurándolo de los residuos de un léxico que fue apto para las necesidades de épocas pasadas". (CIS-73).

Para Gadamer, por el contrario, la hermenéutica es el camino que nos permite recuperar aquella tradición de la filosofía pre-epistemológica, que no toma su orientación de los objetivos que "nosotros" tengamos, sino de la clásica concepción de "lo bueno", ámbito práctico en el cual el pensamiento nos reserva aún una función sistemática e integradora, y no de mera fuga hacia el terreno estético-poético de "lo privado".

En definitiva, Gadamer piensa que la filosofía hermenéutica, no ha sido nunca capaz de trascender las limitaciones de sus propias posibilidades de conocimiento, sin embargo, no necesita por ésto resolverse en el diletantismo cultural que Rorty preconiza. Insertar nuestro pensar en el fluir del acontecer; asumir la fugacidad del devenir en esa tensión donde Verdad y Libertad no se excluyen sino que se armonizan en un horizonte cada vez más amplio, no implica necesariamente renunciar al concepto: que la filosofía reconozca la historicidad de la razón significa ya que la razón no se ha disuelto en la pura historicidad. No es una teoría a priori. Pero tampoco se agota en una "descripción de lo que somos en la actualidad". Formula en fin, una teoría de la historicidad y de la naturaleza finita de toda teoría, a la vez que acepta su propia relación con la fundamental relatividad de todo conocer.

"No tenemos la elección de ser dioses u hombres; y como hombres no estamos como lo divino siempre 
en vela, sino como seres corporales. Como hombres somos siempre también un hombre entre hombres, un ser social, y sólo de la praxis de este ser hombre puede uno o el otro-de vez en cuando, un rato-dedicarse al conocimiento puro". ${ }^{11}$

${ }^{11}$ Gadamer, H.G., Elogio de la teoría, Barcelona, Península, 1993, p. 42. 